\title{
Counting in the verbal domain
}

\author{
Contagem no domínio verbal
}

Susan Rothstein ${ }^{\star}$

\begin{abstract}
This paper argues that the telic/atelic distinction cannot be reduced to a distinction between countable and non-countable predicates in the verbal domain. I show that telic and atelic predicates behave alike with respect to most countability tests and that both are cumulative. No verbal predicates, whether telic or atelic, can be directly modified by cardinal numerals, but all can be modified by a numeral together with the classifier time(s). I suggest that VPs do not denote countable sets. However, VPs, and in particular telic VPs, may denote sets of individuable events, making telic VPs similar to object mass nouns since the entities in the denotations of these VPs are individuable but not countable. Two general conclusions can be drawn from this. First, the contrast between atelic and telic predicates should be formulated in terms of constraints on individuability, not countability. Second, contrary to, e.g. Bach (1986), the mass/count distinction does not structure the verbal domain, and thus, in languages such as English, the nominal and verbal domains are very different.
\end{abstract}

\section{Resumo}

Este artigo defende que a distinção télico/atélico não pode ser reduzida a uma distinção entre predicados contáveis e não contáveis no domínio verbal. Demonstro que predicados télico e atélico se comportam da mesma forma em relação à maioria dos testes de contabilidade e que ambos são cumulativos. Nenhum predicado verbal, télico ou atélico, pode ser diretamente modificado por numerais cardinais, mas podem ser modificados por um numeral junto com classificadores de tempo. Sugiro que VPs não denotam conjuntos contáveis. No entanto, VPs, e em particular VPs télicos, podem denotar conjuntos de eventos individualizados, tornando VPs télicos similares a nomes de massa objeto, já que as entidades na denotação desses VPs são individualizadas, mas não contáveis. Duas conclusões gerais podem decorrer daí. A primeira é o contraste entre predicados télicos e atélicos que deve ser formulado em termos de restrições sobre individualidade e não contabilidade. A segunda, contrária a Bach (1986), prevê que a distinção massivo/contável não estrutura o domínio verbal, e assim, em línguas como o inglês, os domínios nominal e verbal são muito diferentes.

* Bar-Ilan Univeristy - susan.rothstein@biu.ac.il 


\section{Introduction $^{1}$}

his paper reconsiders the claim made by Bach (1986) that the mass/count
contrast surfaces in the verbal domain under the guise of the atelic/
telic distinction. I show, contra this position, that the contrast between atelic and telic verbal predicates cannot be reduced to a contrast in countability. Instead, following Rothstein (2010), I distinguish between individuability and countability, and argue that telic and atelic predicates can be characterised in terms of whether or not they denote individuable events.

The structure of the paper is as follows. In the next section, section 2, I consider two aspects of the argument that the atelic/telic distinction parallels the mass/count contrast. I consider first Bach (1986), who discusses verbal modification, and then Krifka (1989, 1992, 1998), who argues that mass nouns and atelic predicates are cumulative, while count nouns and telic predicates are quantized. In section 3, I show that countability tests, including those discussed by Bach (1986), do not group atelic and telic predicates into two distinct classes. In section 4, I reconsider the cumulativity property, and show that it too does not distinguish between atelic and telic predicates. In section 5, I review arguments from Rothstein (1999), which support the claim that atelic and telic predicates cannot be distinguished using distributive modifying predicates, and show that there is, on the other hand, a strong contrast between verbal predicates and APs. VPs such as be sick in general allow distributive modification, while

\footnotetext{
1 Research for this paper was supported by Israel Science Foundation grant 1345-13 to Susan Rothstein. I should like to thank an anonymous reviewer for helpful comments.
} 
S. Rothstein Counting in the Verbal Domain

minimally contrasting APs such as sick do not. This suggests that VPs, but not APs have individuals in their denotations. In the final section, I suggest that while the atelic/telic contrast is not a contrast in countability, it does involve a contrast in individuability, as originally argued in Rothstein (2004). We know now from multiple researchers (BARNER; SNEDEKER, 2005; ROTHSTEIN, 2010, 2017; SCHWARZSCHILD, 2011; LANDMAN, 2011, 2016 and many others) that mass nouns can be divided into those which are naturally atomic, so-called 'object mass nouns', and those which denote stuff which does not come in inherently individuable units, i.e. 'substance mass nouns'. I argue that in the verbal domain, all verbal predicates are mass, and that the atelic/telic distinction most plausibly parallels the substance/object mass noun distinction, with object mass nouns and telic VPs denoting sets of naturally individuable entities (objects and events respectively), while substance mass nouns and atelic predicates denote sets of entities which do not come with natural criteria for individuating individuals.

\section{Is the telic/atelic distinction a contrast in countability?}

\subsection{Bach: processes vs. events}

The quest for parallels between the nominal and the verbal domain has been a central issue in linguistic theory at least since Chomsky's seminal Remarks on Nominalization (1970). While Chomsky's paper discussed lexical semantics and the mapping between lexical semantics and syntax, formal semanticists have focussed on different aspects of possible parallelism, including countability.

Let us assume that the model for interpreting natural language includes a sorted domain of individuals, including at least the set of entities at type $d$ and the set of events at type e. Nouns denote sets of entities at type $\langle\mathrm{d}, \mathrm{t}\rangle$ and, following Parsons (1990) and Landman (2000), verbs denote sets of events at type $<e, t>$. If the fundamental difference between nominal and verbal predicates lies only in the sortal type of the individual members of the sets they denote, then we might well expect properties of the one domain to be replicated in the other. A striking property of the nominal domain in many languages, including English and Brazilian Portuguese, is that nouns are divided into those which are countable (count nouns), which can be modified directly by numerals as in three cats, and those which cannot be modified directly by numerals (mass nouns), as in \#three muds, \#three furnitures. So, an obvious question is whether, at least in count/mass languages, this distinction is replicated in the verbal domain.

The classification of verbal predicates has traditionally focused on lexical aspect, and in particular on the telic-atelic distinction, i.e. the contrast between

Revista Letras,

Curitiba, UFPR, n. 96, pp.309-333,

jul./dez. 2017 ISSN 2236-0999 (versão eletrônica) 
predicates which lexically specify an endpoint, such as arrive and build a house, called 'telic' and those which do not, such as live in Amsterdam and love my cat, called 'atelic'. These are distinguished by different grammatical properties, in particular temporal modification. Telic predicates are modified by in an hour type adverbials, but not for an hour type adverbials, as in (1), while the opposite is true of atelic predicates, as in (2):

(1) a. We will arrive at Schiphol in an hour/\#for an hour.

b. John built a house in a month /\#for a month.

(2) a. John ran for an hour/\#in an hour.

b. Mary lived in Amsterdam for ten years/\#in ten years.

Telic predicates such as arrive share with count nouns such as cat the property that the singular individuals in their denotations are inherently discrete, and what counts as 'one' (cat, arrival event) is determined independent of context by the lexical meaning of the predicate. What counts as one cat is determined by our knowledge of the meaning of the word cat (cat denotes a property which holds of a small animal that says "meow") and what counts as one event of arriving is determined by our knowledge of the meaning of the word arrive (arrive denotes a property true of an event of changing from not being at a specified location to being at that location). It is thus natural to ask what the relation between telicity and countability is, and more specifically whether telicity can be reduced to countability.

312 Bach (1986) was the first to suggest that the aspectual contrast between atelic and telic predicates is an expression of the mass/count distinction in the verbal domain. He restricts his attention to what he calls 'eventive' predicates, excluding statives such as live in Amsterdam, and he subdivides eventive predicates into processes and events. In the terminology of Vendler (1957/1967), processes include activities such as run and accomplishments with mass or bare plural themes such as drink wine, while events include achievements such as arrive and accomplishments with quantized themes such as drink three glasses of wine.

Bach argues that different quantity modifiers apply to process and event predicates, and these differences parallel the differences between the quantity expressions which modify mass and count nouns. In (3) and (4) the modifiers lots of/a lot (of) and much modify the mass noun wine and the atelic process predicate drink/eat, but not count nouns or telic predicates, as in (5):

(3) a. John drank lots of/a lot of wine.

b. John drank/ate a lot. 
S. RothSTEIN Counting in the Verbal Domain

(5) a. \#much/lots of cat

b. \#John didn't arrive much/ a lot.

c. \#John ate three apples a lot.

Furthermore, both count nouns and telic predicates can be modified by count modifiers, but this is infelicitous with mass nouns or atelic predicates.

(6) a. John ate three apples.

b. John ate an apple three times

c. John arrived (late) three times.

\#John drank/ate/slept three times.

Bach suggests that processes like eat/drink/sleep are modified by noncardinal expressions such as much/a lot because they are essentially mass predicates, while telic predicates denoting events are countable. To the degree that examples like (7) are felicitous, they are the result of coercion, just like drink three wines/coffees, where mass nouns are used as count predicates and are directly modified by cardinals.

\subsection{Krifka: cumulativity vs quantization}

Krifka $(1989,1992,1998)$ argues that the same formal properties of predicates can be used to distinguish count predicates from mass predicates and telic predicates from atelic predicates. Both (singular) count predicates and telic predicates are quantized but not cumulative, while mass predicates and atelic predicates (as well as plural count predicates) are non-quantized and cumulative.

Quantization is defined in (8):

A predicate $\mathrm{P}$ is quantized iff:

$\forall \mathrm{x}[\mathrm{P}(\mathrm{x}) \rightarrow \neg \exists \mathrm{x}[\mathrm{x} \sqsubset \mathrm{y} \wedge \mathrm{P}(\mathrm{y})]$

"If a predicate $\mathrm{P}$ is quantized, no element in $\mathrm{P}$ has a proper part which is also in P."

Singular count predicates such as cat are quantized since a proper part of a cat, for example the cat's front paw, is not a cat. Telic predicates such as arrive and build a house as well as delimited activity predicates like run a mile are
Revista Letras,

Curitiba, UFPR, n. 96 , pp.309-333, jul./dez. 2017 ISSN 2236-0999 (versão eletrônica) 
quantized. An incomplete part of an arriving event or a building-a-house event or a running-a-mile event is not itself an event of arriving or house-building or running a mile, and thus not in the denotation of the relevant predicate. This is why telic predicates induce the imperfective paradox (Dowty 1979), as shown in (9):

(9) a. Mary was arriving at the station DOES NOT ENTAIL Mary arrived at the station.

b. Jan was building a house DOES NOT ENTAIL Jan built a house.

A sentence using the progressive makes reference to a part of an event including proper parts, and since telic predicates are quantized, a proper part of an event in VP cannot itself be an event in VP. Thus, the entailments in (9) do not go through. In this respect, telic predicates and singular count predicates are similar.

In contrast, mass predicates such as water and atelic predicates such as run are not quantized, and proper parts of a quantity of water are considered water, while proper parts of an event of running are running events (as long as the parts are above a certain minimal size). As opposed to (9), entailments from the progressive to the simple past hold, as long as the event witnessing the entailing $\mathrm{S}$ is above the minimal size:

Mary was running ENTAILS Mary ran.

The positive property characterizing atelic predicates and mass predicates (as well as plural count predicates) is cumulativity:

A predicate $\mathrm{P}$ is cumulative (upwardly homogeneous) iff: $\forall \mathrm{x} \forall \mathrm{y}[\mathrm{P}(\mathrm{x}) \wedge \mathrm{P}(\mathrm{y}) \rightarrow \mathrm{P}(\mathrm{x} \sqcup \mathrm{y})]$

"If a predicate $\mathrm{P}$ is cumulative then for any $\mathrm{x}$ and $\mathrm{y}$ in $\mathrm{P}$, the sum of $\mathrm{x}$ and $\mathrm{y}$ is also in $\mathrm{P} "$

The mass predicate water is cumulative since the sum of two quantities of water falls in the denotation of water. The atelic predicate run is cumulative since an event of running from say 13.00 to 14.00 and a second event of running from say 14.00 to 15.00 can be summed to form an event in the denotation of run. A count predicate like cat is non-cumulative, since the sum of two individuals in the domain of cat does not fall in the denotation of cat but in the denotation of the plural predicate cats. A similar argument makes build a house non-cumulative, since a sum of singular events in build a house is not in the denotation of build a house. Note that atelic predicates such as run can be made 
S. Rothstein Counting in the Verbal Domain

telic and quantized by the addition of delimiting modifiers, as in run a mile, just as mass nouns like water can be made into quantized predicates by the addition of quantity modifiers, as in two litres of water. As Krifka writes: "If we have two events of running, then they form together an event of running; and if we have an event of running a mile, then no proper part of it is an event of running a mile." (Krifka 1992, p34).

There has been considerable discussion in the literature about whether quantization is the property which defines singular count nouns (see e.g. Zucchi and White 2001, Rothstein, to appear). It has often been noted that there are various cases in which quantization fails to characterise count nouns appropriately, in particular there are non-quantized count nouns such as line, plane (MITTWOCH, 1985), sequence and twig (KRIFKA, 1992), fence, wall, and hedge (ROTHSTEIN, 1999, 2010). There is, however, agreement about the intuition underlying the use of quantization as a defining property: singular count nouns denote sets of contextually discrete minimal entities, which results in these predicates being countable, while mass nouns and plural count nouns are cumulative.

Against this background, we can now formulate our central question: is cumulative vs. non-cumulative reference, as expressed in the contrast between mass nouns and singular count nouns, also at the basis of the atelic/telic distinction in the verbal domain? In the next section I will show that the atelic/telic contrast in fact does not parallel the mass/count contrast. In section 4, I will consider cumulativity in the verbal domain and show that the atelic/telic contrast cannot be expressed in terms of cumulativity.

\section{Do telic and atelic predicates show differences with respect to countability?}

Our first observation is that contrary to what Bach (1986) suggests, all lexical aspectual categories of VPs can be modified by counting expressions like three times. (12) gives examples of telic VPs which can easily be modified by numericals, but (13) shows that atelic predicates can also be easily modified by these expressions.

(12) a. John jumped three times.

(semelfactive)

b. Mary has written a book three times.

(accomplishment)

c. I have landed in_São Paulo airport three times.

(achievement)

Revista Letras,

Curitiba, UFPR,

n. 96, pp.309-333,

jul./dez. 2017

ISSN 2236-0999

(versão eletrônica) 
(13) a. I have been in Brazil three times.

b. I haven't slept more than three times this week! (activity)

c. Bill has drunk whisky three times. (activity)

d. I only smoked once in my life! (activity)

Clearly the examples in (13) are atelic as they can be modified by fortemporal expressions, as in be in Brazil for a week, sleep for twelve hours and so on, but the counting modifier is still completely natural. Bach suggests that counting atelic predicates, when it is possible, is the result of the same coercion which allows us to say things like I drank three beers, but the two processes do not look the same. The coercion which allows the mass-to-count shift in the nominal domain requires a conventionalised division into portions. (14a) is felicitous, especially in a restaurant context, as is (14b), but the portions must be conventional portions, even if they are not all the same size. Examples like (14c) are infelicitous because servings or portions of water are not usually determined by saucers or cups. Different lexical items are open to portion readings to different degrees. (14d) has a plurality of kinds reading as its first reading, and the portion reading is secondary. (14e) is infelicitous without heavy contextual support.

(14) a. I drank two coffees (a large one and a small one).

b. Last night I drank three beers (one pint and two half-pints).

c. \#They brought three waters, a saucer of water, a glass of water and a cup of water.

d. Last night I drank three wines.

e. $\quad$ \#The nurse wiped up three bloods.

In contrast, the examples in (13) are all acceptable without any supporting context and, crucially, without any information about what the dimensions of the counted events actually are. (13c) may tell us that there were three occasions on which Bill drank whisky, but not how long these whisky-drinking events were or how much whisky was drunk. This suggests that the process allowing counting of atelic eventualities is very different from coercion, which allows mass nouns to denote countable portions.

Our second observation is that numerals never directly modify any verbal predicates, but must combine with times, as in all the examples in (12) and (13). This contrasts with the nominal domain, where numerals directly modify count nouns, as in three cats, but only modify mass nouns in conjunction with a 
S. RothsteIN Counting in the Verbal Domain

classifier, as in three bottles of wine, three litres of wine, three pieces of furniture. As a consequence, the numeral phrase modifying a telic accomplishment, as in read War and Peace three times, looks grammatically like a counting phrase in the mass domain where the numeral has to combine with a classifier before modifying the noun, rather than like counting in the count domain where the numeral combines directly with the noun. (There are three special lexical items once, twice and thrice, which modify VPs directly, but these are completely interchangeable with one time, two times and three times, and suggest that time has been incorporated into their meaning.)

Landman (2006) argues that there is good semantic evidence to assume that time in three times is functioning like a classifier. He starts from Rothstein's (1995) account of examples like (15), where time appears as a head in quantificational adverbials like (15a), as well as in definite NP adverbials like (15b).

(15) a. I opened the door every time the bell rang.

b. I opened the door the three times that the bell rang.

Rothstein (1995) assumes that the domain of individuals IND is sorted into (at least) entities and events, and argues that time is a sortal which denotes the set of events $E \subseteq$ IND. In (15), time is the head of the relative clause and thus binds the trace in the adverbial position in the relative clause, as in (16).

$$
\text { every/the three [timesi (that) the bell rang } \mathrm{t} 1 \text { ] }
$$

Semantically, times guarantees that the trace denotes a variable in the domain of events.

Landman (2006) argues that while the expressions in (15) are indirect counters for events, three times is a direct counter. He shows that three times must be a quasi-intensional modifier which imposes what he calls a grid structure on the denotation of the VP predicate. This must be the case because (17) is ambiguous:

Susan reviewed two papers three times.

This can be true either if there were three different groups of two papers, each of which Susan reviewed (on three occasions she was asked to review two papers) or if there were two different papers each of which Susan reviewed three times (each of these papers was sent to her separately three times, maybe by three different journals). Thus, put in oversimplified terms, Landman argues that three times does not simply count events, but does so by first picking out the sets of events which count, contextually, as one. In the case of (17), the events

Revista Letras,

Curitiba, UFPR, n. 96 , pp.309-333, jul./dez. 2017 ISSN 2236-0999 (versão eletrônica) 
counted by three times can be either events of reviewing two papers or events of reviewing a single paper. The details of Landman's analysis are too complicated to discuss here, but the effect is that times indeed has the semantics of a classifier in that it maps a set of events onto a set of countable events by deciding what counts, in context, as one event. But if this is the case, then, since all VPs are modified by $n$ times and not by bare numerals, it seems that all VPs are counted via classifier constructions, in which case they are all more like mass predicates than count predicates.

Count noun plural predicates can be counted via classifiers, as in (18a), but can also be counted without a classifier, as in (18b). Individuating sortal classifiers in the count domain are not acceptable, as in (18c):

(18) a. three groups of chairs

b. three chairs

c. \#three units of chair

In the verbal domain, a structure analogous to (18b) is impossible and a classifier time, is used in both singular and group readings.

Our third observation focusses on the interpretation of a lot as in (19):

(19) a. I landed at Schiphol a lot last year.

b. I ran a lot yesterday.

c. \#I wrote a paper a lot yesterday.

A lot can modify both telic and atelic predicates, but not necessarily with the same interpretation. In (19a), where the VP is telic, a lot has a 'plurality of events' reading, and (19a) asserts that there were many events of my landing at Schiphol last year. This interpretation seems to be equivalent to many times and often, and thus suggests a count-like interpretation of the VP. In (19b), where the VP is atelic, the natural interpretation is that I did a lot of running in a single event. Singular telic events cannot usually be modified by a lot, as in (19c). However, atelic verbs also allow a plurality of events interpretation of a lot, as in (20).

(20) a. I ran a lot, in fact every day.

b. I drink wine a lot, but never very much at any one time.

If the plurality of events interpretation of a lot is available with atelic VPs, then, according to Bach (1986), they have properties which they share with telic predicates and count nouns. 
S. RothsteIN Counting in the Verbal Domain

Finally, a fourth relevant observation concerns comparatives. As is well known, the comparative operator more can be used with both VPs and with NPs, as in (21). In (21a), where more modifies a count noun, the comparison is in terms of cardinality, and (21a) is true only if the number of sandwiches that Mary ate is greater than the number of sandwiches that John ate. In (21b), where the noun is mass, the comparison is in terms of volume (i.e. in terms of extent). In (21c), where more modifies a telic VP, the comparison is in terms of cardinality, comparing numbers of landing events, and thus similar to the count comparative in (21a). However, in (21d), where more modifies an atelic V, the comparison can be either in terms of cardinality, comparing number of running events (similar to (21a)), or in terms of extent, comparing the extents of two singular running events, (similar to the mass comparative in (21c)):

(21) a. Mary ate more sandwiches than John.

b. Mary ate more bread than John.

c. Mary landed at Schiphol more than John did.

d. Mary ran more than John.

While, this seems to strengthen the parallel between atelic predicates and mass nouns on the one hand and telic predicates and count nouns on the other, downward comparisons add an extra dimension. English uses fewer for comparing count nouns and less for comparing mass nouns, as in (22):

(22) a. John read fewer $/{ }^{\star}$ less books than Mary.

b. John drank less $/{ }^{\star}$ fewer wine than Mary.

Strikingly, all VPs, whether telic or atelic are compared with less, as shown in (23). Note that the comparisons in (23a-c) can be in terms of length of activity or cardinality of events, while in (23d), where the predicate in an achievement verb, comparison can only be in terms of cardinality of events.

(23) a. John ran less than Mary (did).

b. John lived in Amsterdam less than Mary.

c. John read books less than Mary (did).

d. John lands at Schiphol less than he lands at Heathrow.

Telic predicates with direct objects also show a contrast between cases where theme argument and the VP are compared, as in (24). The comparative word used to compare the theme depends on the mass/count status of the theme, while comparison of the VP always uses less: 
(24) a. John built fewer houses than Mary.

b. John built houses less than Mary.

Unambiguous comparisons of event cardinalities with non-achievement verbs are expressed by using fewer and the classifier times, as in (25a/b), while frequency (but not necessarily cardinality) can be compared using less often), as in $(25 c)$ :

(25) a. John ran fewer times than Mary.

b. John built houses fewer times than Mary.

c. John ran less often than Mary.

We will return to the interpretation of these sentences later. For now, what is relevant is that all VP comparisons behave in the same way with respect to choice of comparative operator, and the operator that is used is the operator used to compare mass nouns.

At this point, we have four pieces of evidence which seem to conflict with each other. (i) All VPs, whether telic or atelic, can be modified by a lot with a plurality of events readings (a count-like property). (ii) All VPs, whether telic or atelic, can be modified by three times (also, superficially a countlike property). (iii) However, three times is a classifier phrase, and the data thus suggests that all counting of VPs requires a classifier (a mass-like property). (iv) Finally, all downward comparisons use the mass operator less, (also a masslike property). Crucially, it seems that all VPs behave more or less in the same way with respect to each test, but with contradictory results with respect to countability. This suggests that verbal predicates cannot be categorised into two groups with respect to countability, and further, that we cannot obviously easily categorise VPs as either count or mass since they have properties of both. The only property consistently differentiating atelic event predicates from telic predicates, is that only atelic predicates can be modified by a lot when they denote sets of singular events. Before discussing this further, we will look in more detail at cumulativity and quantization.

\section{Cumulativity and quantization in the nominal and verbal domain.}

If telic and atelic predicates show similar behaviour in counting and quantity modification contexts, then why do they apparently show different behaviour with respect to cumulativity and quantization? Close examination shows that testing VPs for cumulativity does not clearly distinguish between telic and atelic predicates. Furthermore, it does not explain why, to quote Krifka, 
S. Rothstein Counting in the Verbal Domain

two events of running "form together an event of running" (KRIFKA, 1992, p. 34), while two events of running a mile do not form an event of running a mile.

Cumulativity in the nominal domain is about plurality. The definition of cumulativity, given in (11) and repeated here in (26), defines a cumulative predicate as one which is closed under sum, i.e. for any two entities in its denotation the sum of those entities is also in its denotation.

A predicate $\mathrm{P}$ is cumulative (upwardly homogeneous) iff: $\forall \mathrm{x} \forall \mathrm{y}[\mathrm{P}(\mathrm{x}) \wedge \mathrm{P}(\mathrm{y}) \rightarrow \mathrm{P}(\mathrm{x} \sqcup \mathrm{y})]$

"If a predicate $\mathrm{P}$ is cumulative, then for any $\mathrm{x}$ and $\mathrm{y}$ in $\mathrm{P}$, the sum of $\mathrm{x}$ and $\mathrm{y}$ are also in P."

Mass nouns and plural count nouns are cumulative because they are closed under sum, and thus the sum of two quantities in the set they denote is also in that set, independent of whether the sum is spatially continuous or discontinuous, as shown in $(27 \mathrm{a} / \mathrm{b})$. The wine and the books in these examples denote the sum of the entities brought by John and Mary. Singular count nouns are not cumulative because they are not closed under sum, as shown in (27c).

(27) a. John brought wine and Mary brought wine. The/that wine is for dinner.

b. John brought books and Mary brought books. The books are for Bill.

c. \#John brought a book and Mary brought a book. The book is for Bill.

The contrast is not minimal, since English requires an indefinite article, but (27c) still shows that a sum of two items in the denotation of book cannot also be in book.

Plural nouns and mass nouns will always be cumulative since they are closed under sum. Since verbal predicates, whether telic or atelic, include both singular events and pluralities of events in their denotations, they too should be cumulative. Thus, an event of John landing at Schiphol airport on Monday and an event of his landing at the same airport on Tuesday, as well as the sum of these two events, are all in the denotation of land at Schiphol airport. Event predicates like eat an apple can denote pluralities of events, for example when they distribute over plural subjects, as in John and Mary ate an apple. As we have already seen in (19a) and (20), and repeated here in (28), the availability of the plural interpretation of the VP for both telic and atelic VPs means that it can be modified by a lot with a plurality of events interpretation, as well as by the adverb often. 
(28) a. John landed at Schiphol airport often.

b. John ran often.

Plural interpretations do not need to be explicitly marked by an adverbial or a plural subject, with either telic or atelic predicates. The question When did you VP? presupposes that an event of your doing VP has taken place, but allows for a single date or a plurality of dates as an answer, depending on whether what witnesses the answer is a singular event or a sum of events, as seen in (29):

(29) a. Question: When did you read War and Peace?

Answer 1: In 1972

Answer 2: In 1972 and in 1996.

b. When were you in Brazil?

Answer 1: Only in 2008.

Answer 2: In 2008, 2011 and 2016.

c. When did you eat an apple?

Answer 1: On Monday morning.

Answer 2: On Monday morning and on Tuesday morning.

So, as far as cumulativity is concerned, both atelic and telic VPs are cumulative, in the same way that plural and mass nouns are. Cumulativity cannot be at the root of the atelic/telic distinction, since all VP predicates are 322 closed under sum, whether telic or atelic.

What then, is the relevance of the fact that, to quote Krifka, two events of running "form together an event of running" (Krifka 1992, p34), while two events of building a house or running a mile do not form an event which falls under the same denotation? In this respect, atelic and telic predicates do seem genuinely to differ, as seen in the contrast between (30), on the one hand, where the predicate is atelic, and (31) and (32) on the other, where the verbal predicate is telic:

(30) John ran from $1 \mathrm{pm}$ to $2 \mathrm{pm}$ and he ran/carried on running from $2 \mathrm{pm}$ to $3 \mathrm{pm}$.

- So John ran (once) from 1:00 pm to 3:00 pm.

- So he ran for two hours.

- So he was still running at 2:00 pm/2:30 pm.

(31) John arrived at Schiphol at 1:00 pm and at 2:00 pm.

- So he arrived twice. 
S. RothsteIN

Counting in the

Verbal Domain

- \#So he was still arriving at 2:00 pm.

- \#So he arrived for two hours.

John wrote an essay last week. And he wrote an essay this week.

- So he wrote an essay twice/wrote two essays.

- \#So he wrote an essay for two weeks.

- \#So he was still writing an essay this week.

The answer is that this contrast is not a contrast in cumulativity, since the issue is not whether the (plural) sum of two events in P is also in P. Rather, the question is whether pluralities can, under appropriate conditions, be put together to make a bigger single event. In (30), crucially, two singular events in run are put together to form a new singular event in run. (31) and (32) show that this is what cannot be done with arrive and write an essay. Rothstein (2004), observing this contrast, suggested that atelicity should be defined in terms of a property called S-cumulation. A predicate $\mathrm{P}$ is S-cumulative if it allows two events e1 and $\mathrm{e} 2$ in $\mathrm{P}$ to be summed and then mapped onto a new singular event temporally co-extensive with e1பe2. (30) shows that run is S-cumulative, while arrive at Schiphol and write an essay are not.

S-cumulativity distinguishes between predicates denoting events which can be extended temporally, and those which cannot. At first sight, it seems that we have finally managed to recreate the mass/count distinction in the verbal domain. Singular events in the denotation of atelic predicates like run can be extended indefinitely, in the same way that single quantities of water can be added to indefinitely, and can still remain single quantities of water. Telic predicates like write an essay/land at Schiphol cannot be extended in this way, just as an entity in the denotation of chair or pen cannot be indefinitely extended. However, even S-cumulativity does not distinguish telic from atelic predicates. Telic predicates fail to be S-cumulative only when the theme argument is either singular or modified by a numeral with an exactly interpretation. While (33a) is neither cumulative nor S-cumulative, the examples in (33b) are cumulative and S-cumulative.

(33) a. John ate (exactly) one apple.

b. John ate at least one apple/many apples/more than one apple.

Any two events of eating many apples which are temporally adjacent can be put together to form a singular event of eating many apples. An event of eating at least one apple can be extended by the eating of another apple, and it is still an event in the denotation of eat at least one apples/eat more than one apple. But, as (34) shows, these examples are nonetheless telic, since they can be modified by in half an hour and also induce the imperfective paradox.
Revista Letras,

Curitiba, UFPR, n. 96, pp.309-333, jul./dez. 2017 ISSN 2236-0999 (versão eletrônica) 
(34) a. John ate at least one apple/many apples/more than one apple in half an hour.

b. John was eating at least three apples as part of the competition DOES NOT ENTAIL John ate at least three apples as part of the competition.

c. \#John ate at least three apples for half an hour.

Note also that extending (or diminishing) the boundaries of an event in this way is not like extending (or diminishing) the boundaries of a quantity of water. An event of running can only be extended temporally by postponing its end point (possibly indefinitely), i.e. along a directed temporal axis, whereas a quantity in the denotation of a mass noun can be extended in multiple directions. As a correlate, a quantity of water can be split in any way into two quantities of water, e.g. by plunging a bowl into it and removing the water caught in the bowl. An event of running can only be split into two events of running by separating a final part from an initial part. So, an event of running from 1:00 pm to $4: 00 \mathrm{pm}$ can be split into an event of running from 1:00 pm to 2:00 pm and from 2:00 pm to 4:00 pm, but extracting a single event of running from 2:00 $\mathrm{pm}$ to 3:00 pm will not split the original event into two events, but into three.

The conclusion is that neither cumulativity nor S-cumulativity can be used to characterise the contrast between telic and atelic predicates, and that, as a consequence, the parallels between atelic predicates and mass nouns and between telic predicates and count nouns are only superficial.

324 Intuitively, atelic predicates do seem to be characterised by the fact that they can be indefinitely extended. Dowty (1979) and Rothstein (2004, 2008a) show that activities can be treated as iterations of minimal activities, reanalysed as a single event. An extended event in run is composed out of stringing together temporally overlapping minimal events of running, reanalysed as a single event. Since the iteration has no limit, the event is potentially infinitely extendable and atelic. However, as Landman and Rothstein (2012a,b) show, what is crucial in defining an atelic VP, is that the properties expressed by both V and VP must be applicable both to the event as a whole and to its parts. This property is termed "incremental homogeneity", and guarantees extendibility of an event. If a predicate is incrementally homogeneous, it can be indefinitely extended on the temporal axis. 2 Thus, run in the park is incrementally homogenous and atelic since all parts of the event are both running events and running-in-the-park events, but run a mile is not, since its proper parts are running events but not running-a-mile events.

2 These issues raise fundamental questions about event identity too complex to discuss here. See Landman 1992, 2008, who shows that event semantics requires a concept of cross-temporal event identity, which allows an event to be extended in time while remaining the same singular event. 
S. Rothstein Counting in the Verbal Domain
We can use this to explain why a non-plural, extent reading of a lot is available in (35a) but not in in $(35 b, c)$ :

$\begin{array}{lll}\text { (35) } & \text { a. John ran a lot yesterday. } & (=19 b) \\ \text { b. } & \text { \#John wrote a paper a lot. } & (=19 \mathrm{c}) \\ \text { c. } & \text { \#John ran a mile a lot. } & \end{array}$

In (35a), a lot modifies the incrementally homogeneous run. John's running can be analysed as a single event composed out of multiple minimal running events and a lot, as a VP modifier, adds the information that the singular run event is composed of many events of the same type as the VP. Thus, in a sense, the extent reading of a lot reduces to the plurality reading, since the singular event witnessing (35a) is constructed out of a large plurality of minimal events. In $(35 \mathrm{~b}, \mathrm{c})$ this extent reading is not possible since run a mile and write a paper are not composed of multiple events of the same type. If the direct object in (35b) is deleted, a reading parallel to (35a) becomes possible:

$$
\text { John wrote a lot yesterday. }
$$

The singular event interpretation of a lot is possible only with activities and not with states, even though states are also atelic. The examples in $(37 \mathrm{a}, \mathrm{b})$ have only a plurality of events reading in which a lot is semantically equivalent to often.

(37) a. Mary knew the answer a lot. (= she knew the answer often, not for a long time)

b. The sock lay under the bed a lot (= it lay there often, not for a long time)

The example in (38) illustrates an additional use of a lot, as a modifier of intensity.

$$
\text { Mary hated John a lot. }
$$

Arguably, it can also have the plurality of events reading, in which Mary hated John on multiple occasions. However, it cannot have the extended event reading parallel to (35a), in which the sentence asserts that Mary hated John for a long time, i.e. that her hating John consisted of an extended continuous string of multiple hating events. This strongly suggests that the extended iteration reading in (35a) and (36), is triggered by the semantic properties of activity predicates and not by atelicity in general.
Revista Letras,

Curitiba, UFPR, n. 96 , pp.309-333, jul./dez. 2017 ISSN 2236-0999 (versão eletrônica) 


\section{APs vs VPs}

Before returning to countability in the VP domain, we review briefly data from Rothstein (1999), which clarifies that VPs do indeed denote sets of possibly individuable events, which can be modified by distributives and other predicates sensitive to individuability.

Rothstein (1999) looks at the minimal contrasts between two kinds of small clause complements of verbs like make, those small clauses where the predicate is a VP, and those where it is an AP. All VP predicates, whether telic or atelic, can be counted, can be modified with a plurality-of-events reading, and can be temporally located, while none of these properties hold of AP complements, even when the syntactic difference is minimal. The fact that the predicates are in small clauses, and thus are not marked by tense or aspect shows that the contrast really is between the VP, which denotes a set of individuable events, and the AP, which denotes a state. We cite the central examples here, referring the reader to the original paper for extended discussion and analysis. (39) shows that bare VPs can be modified. In (40), the small clause has an AP predicate, and three times can only modify the matrix verb. The reading is infelicitous because the framing PP suggests that there was only one event of making.

(39) a. With one spell, the witch made John know the answer three times.

b. In one moment John be miserable/sick three times.

$$
\text { \#In one moment, the witch made John miserable/sick three }
$$
times.

Three other properties correlate with this. VP predicates, including atelic predicates, can be temporally located, while AP predicates can never be temporally located. (41a) is acceptable since yesterday can modify make while today can modify know the answer/be sick. (41b) is unacceptable since the AP cannot be modified by a temporal adverbial, and so today can only modify make, which is infelicitous since make is also modified by yesterday.

(41) a. Yesterday, the witch made John know the answer/be sick today.

b. \#Yesterday, The witch made John sick on today.

The every time quantifiers, illustrated in (15) above, can modify atelic as well as telic predicates, but can never modify APs. (42a) is compatible with there being one causing event which caused her to worry whenever the bell rang (e.g. 
S. RothsteIN Counting in the Verbal Domain

I told her that when the bell rang it might be a burglar). (42b) can only mean that each time the bell rang I did something which made Jane nervous.

(42) a. I made Jane worry/be worried/ be nervous every time the bell rang.

b. I made Jane nervous every time the bell rang.

Finally, floating distributive quantifiers can attach to atelic VPs, but not to APs:

(43) a. The medicine made Jane and Mary each be sick.

b. \#The medicine made Jane and Mary each sick.

The conclusion is that VPs, whether telic or atelic, are modifiable by predicates which distribute over individuals as well as being modifiable by three times. APs do not denote sets of individuable entities, and these distributive modifiers cannot modify APs.

\section{Countability in the verbal domain}

We saw in section 2 that all VP predicates can be modified by counting modifiers, but that none can be directly modified by numerals. All VP predicates need the intervention of a classifier-like element times. All VP predicates can be modified by a lot with a plurality of events reading, as well as, for activities, an extended event reading. Furthermore, all VP predicates can be compared using less than, while fewer than is never acceptable except in conjunction with $\mathrm{n}$ times.

VPs then generally show apparently contradictory properties. On the one hand they have individuals and pluralities of individuals in their denotations, as shown by the plurality-of-events reading which is always available with often, a lot and more than. On the other hand, they cannot be counted without the classifier times, which, as we saw in example (17), chooses what counts as a single event in the relevant context, and they can only be compared using less.

This configuration of properties is very like the properties associated with object mass nouns, also called naturally atomic mass nouns (ROTHSTEIN, 2010), and neat mass nouns (LANDMAN, 2011, 2016). These are nouns like furniture, livestock, poultry, kitchenware, jewellery which denote sets of individuable entities, but which are not countable. We know they are not grammatically countable, since \#three poultry, \#three livestock, \#three furniture(s) and similar examples are infelicitous. Countability is only possible if a classifier is used, as in three pieces of furniture, three head of livestock. However, there are several pieces
Revista Letras,

Curitiba, UFPR, n. 96, pp.309-333, jul./dez. 2017 ISSN 2236-0999 (versão eletrônica) 
of evidence that object mass nouns denote sets of individuals. First, as shown by Rothstein (2010) and Schwarzschild (2011), these nouns can be modified by distributive adjectives like big as in the big furniture/livestock, and some expensive jewellery where big distributes over individual pieces of livestock or furniture and expensive distributes over individual pieces of jewellery. Similarly, lots of furniture/livestock is synonymous with a lot of pieces of furniture or many head of livestock. Second, a number of researchers, starting with Barner and Snedeker (2005), have shown that object mass nouns allow for comparisons in terms of cardinality. However, Grimm and Levin (2012), Rothstein (2017), Pires de Oliveira and Rothstein (2017) have all shown that object mass nouns differ from count nouns. While count nouns force comparison in terms of cardinality, object mass nouns allow comparisons along any contextually relevant dimension including the cardinal dimension. Thus (44a) must have a cardinal comparison, while the object mass noun allows either a cardinal or a volume comparison. If John has a grand piano, a huge cupboard and a sofa, while Bill has five folding chairs, then (44a) is false, no matter what the context. However, (44b), is naturally judged true, with the parenthetical material setting the context for a comparison in terms of volume. 3

(44) a. John has more pieces of furniture than Bill.

b. John has more furniture than Bill, (so he will need the bigger moving truck).

The same effects show up in the comparatives with atelic predicates in 328 (45), with context determining whether a cardinal comparison or a comparison in terms of extent is more appropriate.

(45) a. Last week, Mary ran more than John.

b. Last week, Mary practiced the piano more than John.

(45a) can be true if on the one occasion on which they ran, Mary ran a distance greater the distance John ran, in which case the comparison is in terms of temporal length, but can also be true if Mary ran on more occasions, a cardinal interpretation. (45b) is most naturally interpreted in terms of occasions.

Similar parallels show up with comparisons with less. Although object mass nouns allow cardinal comparisons, they can only be modified by the mass comparative less, as in (46a), while the countable classifier construction is modified by fewer, like a count noun $(46 \mathrm{~b}, \mathrm{c})$ :

(46) a. John has less furniture than Bill/ /\#fewer furniture than Bill.

b. John has fewer pieces of furniture than Bill /\#less pieces of furniture than Bill.

c. John has fewer chairs than Bill /\#less chairs than Bill.

3 See Rothstein (2017), chapter 5 for detailed discussion. 
S. RothsteIN Counting in the Verbal Domain

Less furniture in (46a) allows for either the cardinal or the volume interpretation, while fewer pieces of furniture in $(46 \mathrm{~b}, \mathrm{c})$ allows only the cardinal reading.

VPs, as we discussed in section 2 only allow comparison with less, but as with the object mass nouns in (46a), and the VP comparatives in (45), the comparison can be either in terms of cardinality or along a continuous dimension.

VPs, then, - both telic and atelic - look very similar to object mass nouns in terms of countability. Like object mass nouns, VPs denote sets of events which are not countable, but they make available sets of individuals which, in context, are available for cardinal comparisons, modification by often, plurality-of-event readings of a lot and so on. As with object mass nouns, counting requires the mediation of a classifier, in this case, the event-specific classifier time(s).

Telic predicates differ from atelic predicates since they are not incrementally homogeneous. This means, for example, that a lot always as has a plurality of events interpretation when modifying telic predicates, and the effect is to make these telic predicates seem 'more easily countable' than atelic predicates. Rothstein (2008b) gives an explanation of this. The telic/atelic distinction is related to the availability of criteria for event individuation. Telic predicates are those that make explicit what may count as one individual event and thus make individuable events easily salient, while atelic predicates, which are incrementally homogeneous, do not. In (47a), the VP is telic, and we are told what counts as an individual event, namely an event of drinking a single glass of wine. In $(47 b, c)$, the VP is atelic, and we rely on context and real world knowledge to determine what counts as an individual event of drinking wine or running. This knowledge is a precondition for judging whether this kind of event happens often.

(47) a. John drinks a glass of wine often.

b. John drinks wine often.

c. Mary runs often.

So, telic predicates always make a set of individuable events salient, but, as research on object mass nouns has shown, the salience of a set of individuable entities does not make that set countable, since countability must be grammatically encoded.

In conclusion, I have argued in this paper that, at least in English, we have no evidence that countability is encoded in any verb meanings, and that the atelic/telic distinction cannot be reduced to an expression of the mass/count distinction in the verbal domain. In the verbal domain, as is the case for mass nouns, countability seems generally to be encoded by the use of verbal classifiers. The patterns of variation in the use and interpretation of verbal classifiers, distributive modifiers in the verbal domain and quantity modifiers such as a lot, suggest that

Revista Letras,

Curitiba, UFPR,

n. 96 , pp.309-333,

jul./dez. 2017

ISSN 2236-0999

(versão eletrônica) 
the atelic/telic distinction is better seen as a contrast in individuability, with telic VPs offering explicit criteria for picking out individuable events, and atelic VPs not doing so. This is in line with Rothstein's (2004) characterization of the different aspectual lexical classes in terms of the different kinds of criteria used for picking out individuable events. On this general approach, lexical aspect, including the atelic/telic contrast is fundamentally concerned with criteria for event individuability.

This allows us to identify a major difference between the nominal and the verbal domains. The major grammatical contrast in the nominal domain in English focusses on the contrast between countable and non-countable, while in the verbal domain the focus is on the contrast between degrees of individuability. This observation reinforces recent work on the mass/count distinction, such as Rothstein $(2010,2017)$ which stresses the distinction between countability and individuability.

The account proposed here raises the obvious question of why the nominal and verbal domains should differ in this way. Why is individuation presupposed and countability grammatically encoded in count nouns, while criteria for individuation must be made explicit in the verbal domain? It is plausible that the answer to this question lies in the fundamental differences between events and objects, but pursuing the issue further is beyond the scope of this paper. 


\section{References}

BACH, E. The algebra of events. Linguistics and Philosophy, v. 9, p. 5-16, 1986.

BARNER, D.; SNEDEKER, J. Quantity judgments and individuation: evidence that mass nouns count. Cognition v. 97, n. 1, p. 41-66, 2005.

CHOMSKY, N. Remarks on Nominalization. In: JACOBS, R.;

ROSENBAUM, P. (Eds.) Readings in English Transformational Grammar. Waltham Mass: Ginn and Company.

1970, P. 184-221.

DOWTY, D. Word Meaning and Montague Grammar. Dordrecht: Springer (Kluwer), 1979.

GRIMM, S.; B. LEVIN. "Who Has More Furniture?” An Exploration of the Basis for Comparison", Conference Presentation Mass/Count in Linguistics, Philosophy and Cognitive Science Conference, École Normale Supérieure, Paris, France, December 20-21, 2012.

KRIFKA, M. Nominal reference, temporal constitution, and quantification in event semantics. In: BARTSCH, R.; VAN BENTHAM, J.; VAN EMDE BOAS, J. (Eds.) Semantics and Contextual Expressions. Dordrecht: Foris. 1989. p.75-115.

KRIFKA, M. Thematic relations as links between nominal reference and temporal constitution. In: SAG, I.; SZABOLSCI, A. (Eds.) Lexical Matters, Chicago: Chicago University Press. 1992. p. 29-53.

KRIFKA, M. The origins of telicity. In: ROTHSTEIN, S. (Ed.) Events and Grammar, Dordrecht: Springer (Kluwer). 1998. p.197-235.

LANDMAN, F. The progressive. Natural Language Semantics vol.1, p.1-32. 1992.

LANDMAN, F. Events and Plurality: The Jerusalem Lectures. Dordrecht: Springer (Kluwer), 2000.

LANDMAN, F. Indefinite time-phrases, in situ-scope, and dual perspective intensionality. In: VOGELEER, S.; TASMOWSKI, L. (Eds.) Non-definiteness and Plurality, Amsterdam, John Benjamins. 2006. p.237-266.

LANDMAN, F. 1066: On the differences between the tense-perspectiveaspect systems of English and Dutch, In ROTHSTEIN, S. (Ed.) Theoretical and Crosslinguistic Approaches to the Semantics of Aspect. Amsterdam: John Benjamins. 2008. P. 107-166.

LANDMAN, F. Count nouns, mass nouns, neat nouns, mess nouns. Baltic International Yearbook of Cognition, Logic and Communication: Volume 6, 2011.

Revista Letras,

Curitiba, UFPR,

n. 96, pp.309-333,

jul./dez. 2017

ISSN 2236-0999

(versão eletrônica) 
LANDMAN, F. Iceberg semantics for count nouns and mass nouns: classifiers, measures and portions, Baltic International Yearbook of Cognition, Logic and Communication: Volume 11. 2016 https://dx.doi.org/10.4148/1944-3676.1107

LANDMAN, F.; ROTHSTEIN, S. The felicity of aspectual for-phrases Part I:

HOMOGENEITY. Language and Linguistics Compass vol. 6, p.85-96, 10.1002/ $\operatorname{lnc} 3.3242011,2012$.

LANDMAN, F.; ROTHSTEIN, S. The felicity of aspectual for-phrases Part II: Incremental homogeneity. Language and Linguistics Compass vol. 6, p. 97-112, 10.1002/lnc3.32320112012.

MITTWOCH, A. Aspects of English aspect: On the interaction of perfect, progressive and durational phrases. Linguistics and Philosophy, v. 11, p. 203254, 1988.

PARSONS, T. Events in the Semantics of English. Cambridge, Mass: MIT Press

PIRES DE OLIVEIRA, R.; ROTHSTEIN, S. Bare nouns in are mass in Brazilian Portuguese. Lingua, v. 121, p. 2153-2175, 2011.

ROTHSTEIN, S. Adverbial quantification over events. Natural Language Semantics, v.3, p.1-31, 1995.

ROTHSTEIN, S. Fine-grained structure in the eventuality domain: the semantics of predicate Adjective Phrases and Be. Natural Language Semantics, v. 7, p. 37-420, 1999.

ROTHSTEIN, S. Structuring Events : A Study in the Semantics of Lexical Aspect.

\section{OXFORD: WILEY-BLACKWELL, 2004.}

ROTHSTEIN, S. Two puzzles for a theory of lexical aspect: the case of semelfactives and degree adverbials. In DÖLLING, J.; HEYDE-ZYBATOW, T.; SHAEFER, M.(Eds.), Event Structures in Linguistic Form and Interpretation. Berlin: Mouton De Gruyter. 2008a. p.175-198.

ROTHSTEIN, S. Telicity, atomicity and the Vendler classification of events. In

ROTHSTEIN, S. (Ed.) Theoretical and Crosslinguistic Approaches to the Semantics of Aspect. Amsterdam: John Benjamins, p. 43-78, $2008 \mathrm{~b}$.

ROTHSTEIN, S. Counting and the mass count distinction. Journal of Semantics, v. 27, p. 343-397, 2010.

ROTHSTEIN, S. Semantics for Counting and Measuring. Cambridge: 
S. RothSTEIN Counting in the Verbal Domain
Cambridge University Press, 2017.

ROTHSTEIN, S. Count vs. mass nouns. In: MATTHEWSON, L.; MEIER, C.; RULLMAN,

H.; ZIMMERMANN, T.E. (Eds.), The Blackwell Companion to Semantics. Malden and Oxford: Wiley/Blackwell. To appear.

SCHWARZSCHILD, R. Stubborn distributivity, multiparticipant nouns and the count/mass distinction. In LIMA, S.; MULLIN, K.; SMITH, B.; (Eds.), Proceedings of the 39th Meeting of the North East Linguistic Society, Amherst: GLSA, p.661-678, 2011.

VENDLER, Z. Verbs and times. The Philosophical Review vol. LXVI, p. 143-160. 1957. Reprinted in a revised version in VENDLER, Z. Linguistics in Philosophy. Ithaca: Cornell University Press, 1967.

ZUCCHI, S; WHITE, M. Twigs, sequences and the temporal constitution of predicates. Linguistics and Philosophy, v. 24, p 223-270. 2001.

Submetido em: $15-08-2017$

Aceito em: 15-08-2017 